\title{
OPTICAL AND ELECTRICAL PROPERTIES OF HIGH TEMPERATURE ANNEALED HETEROEPITAXIAL GaN:Mg LAYERS
}

\author{
M. Wojdak, J.M. Baranowski, B. Suchanek, K. Pakula \\ Institute of Experimental Physics, Warsaw University \\ Hoża 69, 00-681 Warszawa, Poland
}

\section{J. JUN AND T. SUSKI}

High Pressure Research Centre, Polish Academy of Sciences Sokołowska 29/37, 01-142 Warszawa, Poland

In this paper we present for the first time luminescence and electrical measurements of $\mathrm{GaN}: \mathrm{Mg}$ heteroepitaxial layers annealed at very high temperatures up to $1500^{\circ} \mathrm{C}$ and at high pressures of nitrogen up to $16 \mathrm{kbar}$. The presence of high nitrogen pressure prevents $\mathrm{GaN}$ from thermal decomposition. It was found that annealing in the presence of additional $\mathrm{Mg}$ atmosphere leads to a high quality $p$-type epitaxial layer of the hole concentration equal to $2 \times 10^{17} \mathrm{~cm}^{-3}$ and mobility $16 \mathrm{~cm}^{2} /(\mathrm{V} \mathrm{s})$. However, annealing at high temperatures without additional magnesium causes conversion to $n$-type. It is also shown that in the high temperature annealed GaN:Mg epilayers the donor-acceptor luminescence is the dominant recombination channel.

PACS numbers: 78.66.Fd, 78.55.Cr, 73.61.Ey

Recently light emitting diodes based on gallium nitride are in commercial production. In the beginnings, obtaining of p-ype conductivity in GaN was difficult, because this material is intrinsic $n$-type. At least magnesium was found to be an efficient acceptor [1, 2]. In metalorganic chemical vapour deposition (MOCVD) grown layers $\mathrm{Mg}$-acceptors are passivated by hydrogen which incorporates during the growth. To remove it thermal annealing process is required. Usually temperatures between $600-800^{\circ} \mathrm{C}$ are used [2]. However, the properties of $\mathrm{GaN}: \mathrm{Mg}$ layers annealed in temperatures higher than $1100^{\circ} \mathrm{C}$ were never tested before, because the material is not stable above this temperature. But annealing in high temperatures becomes possible under high pressure. In this paper we present electrical and luminescent properties of high-temperature annealed GaN:Mg heteroepitaxial layers.

The GaN layers were grown on the sapphire substrates in the MOCVD system. Trimethylogallium (TMG) and ammonia $\left(\mathrm{NH}_{3}\right)$ were used as sources of $\mathrm{Ga}$ and $\mathrm{N}$, respectively, and the source of magnesium was $\mathrm{Mg}$ metalorganic. Hydrogen was used as a carrier gas. The photoluminescence (PL) was excited by the $325 \mathrm{~nm}$ 
line of a He-Cd laser. The incident power of $1 \mathrm{~mW}$ was used. The emission spectra were recorded using SPEX 500M monochromator equipped with a photomultiplier. Photoluminescence measurements were performed at the temperature $4.2 \mathrm{~K}$. Hall measurements were performed using Van der Pauw method at $297 \mathrm{~K}$ temperature. Ohmic contacts were made of annealed $\mathrm{Ni} / \mathrm{Au}$ metallic layers. Thermal annealing processes were performed in high pressure and high temperature gas system in HPRC PAS.

Three MOCVD layers were used: S85, S131, and S45. The layers were cut into pieces, marked with letters, and annealed at different conditions. Thus, samples S85N, S85M and S85J are the pieces of the same heteroepitaxial layer. Also samples S131C and S131E are the pieces of one MOCVD layer. All the layers before annealing were semi-insulating.

TABLE

Annealing parameters and electrical properties. Samples S85J, S85N, and S85M are the pieces of one MOCVD epitaxial layer. After growth the layer was cut into pieces, which were annealed at different conditions. It concerns also samples S131C and S131E.

\begin{tabular}{c|c|c|c|c|c|c}
\hline \hline Sample & \multicolumn{3}{|c|}{ Annealing } & \multicolumn{3}{c}{ Electrical properties } \\
\cline { 2 - 7 } & $\begin{array}{c}\text { Temp. } \\
{\left[{ }^{\circ} \mathrm{C}\right]}\end{array}$ & $\begin{array}{c}\text { Pressure } \\
{[\mathrm{kbar}]}\end{array}$ & $\begin{array}{c}\text { Time } \\
{[\mathrm{min}]}\end{array}$ & Ambient & $\begin{array}{c}\text { Type of conductivity and } \\
\text { carriers concentration } \\
{\left[\mathrm{cm}^{-3}\right]}\end{array}$ & $\begin{array}{c}\text { Mobility } \\
{\left[\mathrm{cm}^{2} /(\mathrm{V} \mathrm{s})\right]}\end{array}$ \\
\hline S85J & 1500 & 16.5 & 30 & $\mathrm{~N}_{2}$ & $n=6.5 \times 10^{18}$ & 53 \\
S45 & 1300 & 16.5 & 30 & $\mathrm{~N}_{2}$ & semi-insulating & - \\
S85M & 1150 & 3.5 & 60 & $\mathrm{~N}_{2}$ & $n=3 \times 10^{13}$ & 250 \\
S85N & 1000 & 3.5 & 60 & $\mathrm{~N}_{2}$ & $p \approx 10^{15}$ & $\approx 5$ \\
S131C & 1300 & 12 & 10 & $\mathrm{~N}_{2}+\mathrm{Mg}$ & $p=2 \times 10^{17}$ & 8 \\
S131E & 1150 & 12 & 10 & $\mathrm{~N}_{2}+\mathrm{Mg}$ & $p=2 \times 10^{17}$ & 16
\end{tabular}

Table shows annealing conditions and electrical properties of the annealed samples. The lowest temperature used was $1000^{\circ} \mathrm{C}$ and in that case a low concentration of holes was obtained. At the higher temperatures layers were converted to $n$-type conductivity and for $1500^{\circ} \mathrm{C}$ annealing temperature very high concentration of electrons was obtained. It was found that addition of $\mathrm{Mg}$ metal to the ambient during the annealing process can efficiently stop conversion to $n$-type conductivity.

Figure 1 presents the low temperature spectra of the samples. For all the samples luminescence band close to the region of donor-acceptor transitions is dominant. Neither free nor bound excitons have been observed.

Spectrum of unannealed S85 layer is also shown. Its broad shape indicates that $\mathrm{Mg}$ acceptors are compensated by the hydrogen. Typical shape of luminescence related to active acceptors should contain donor-acceptor line and phonon replicas, as reported before $[3,4]$. This kind of spectra have been observed for samples annealed with $\mathrm{Mg}$ vapour (S131E and $\mathrm{S} 131 \mathrm{C}$ annealed at $1150^{\circ} \mathrm{C}$ and $1300^{\circ} \mathrm{C}$, respectively), and for the sample $\mathrm{S} 85 \mathrm{M}$, annealed at $1150^{\circ} \mathrm{C}$ with no magnesium in the ambient.? 


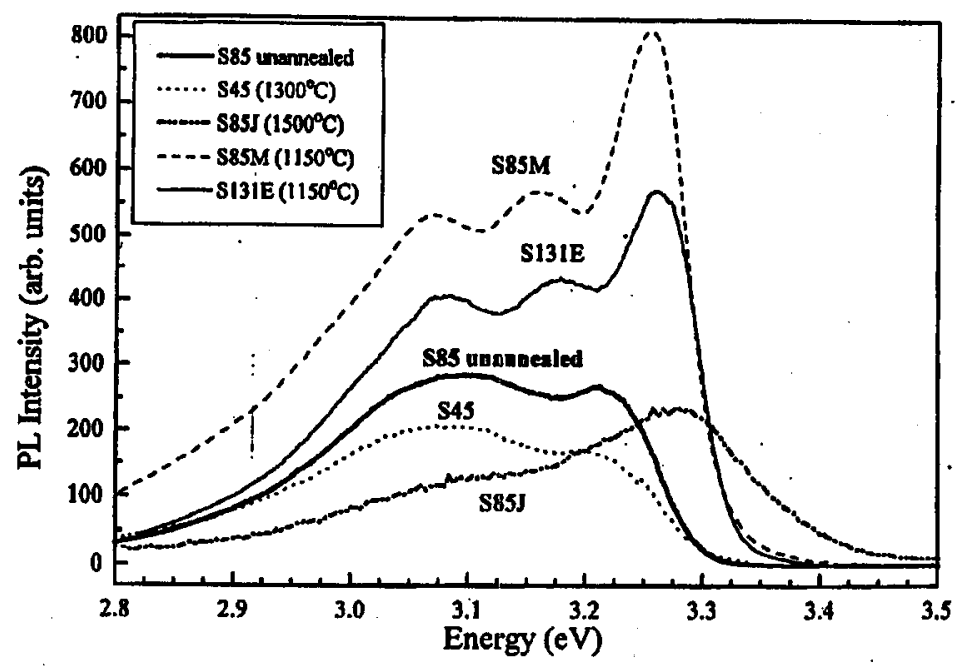

Fig. 1. Photoluminescence spectra of annealed heteroepitaxial GaN:Mg layers. Spectrum of unannealed S85 sample is also shown. Luminescence intensities of the spectra were normalised to show all the details.

Luminescence of the samples annealed at higher temperatures without magnesium vapour converts into a broad bands. No separate lines can be distinguished. The spectrum of the sample S85J annealed at the highest $1500^{\circ} \mathrm{C}$ temperature is even broader and extends to the high energies above the energy gap of GaN. This effect is caused by optical transition from the Fermi level, which in the case of a high electron concentration lies well above the bottom of conduction band. This indicates that during annealing donors were created. Most probably they are formed by in-diffusion of oxygen, as discussed further.

To compare the total intensity of the emission, integrals of luminescence spectra were calculated. Results are plotted in Fig. 2. It is clearly seen that intensity falls down by the orders of magnitude as the annealing temperature is rising. This shows that new recombination channels were created. They could be connected with appearing of yellow luminescence and opening additional nonradiative channels. The presence of yellow luminescence was actually observed on sample S85J, annealed at $1500^{\circ} \mathrm{C}$. However, it seems that a nonradiative channel of recombination dominates. The nature of the nonradiative process is not clear.

The most important result of this experiment is that relatively high hole concentration and mobility was obtained. It concerns samples S131E and S131C with hole concentrations $2 \times 10^{17} \mathrm{~cm}^{-3}$ and mobilities $16 \mathrm{~cm}^{2} /(\mathrm{V} \mathrm{s})$ and $8 \mathrm{~cm}^{2} /(\mathrm{V} \mathrm{s})$, respectively. Thus, the temperature range $1150-1300^{\circ} \mathrm{C}$ and the $\mathrm{N}_{2}$ atmosphere with $\mathrm{Mg}$ vapour seem to be optimal conditions for annealing $\mathrm{GaN}: \mathrm{Mg}$ layers.

However, during high temperature annealing in the atmosphere of $\mathrm{N}_{2}$ with no magnesium added the conductivity converts into $n$-type, and the luminescence in donor-acceptor transitions region becomes broad and weak. These processes 


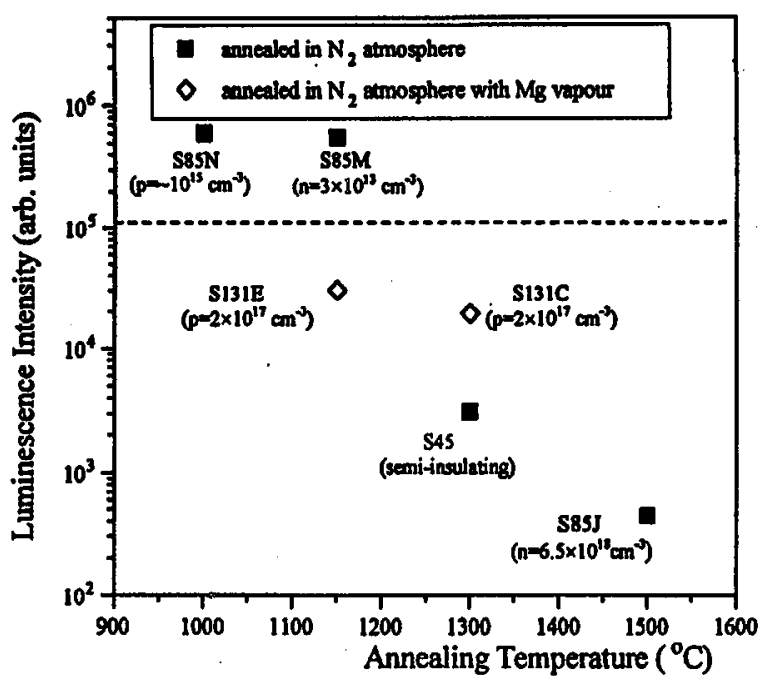

Fig. 2. Total luminescence intensity in function of annealing temperature. Points represent integrals of the photoluminescence spectra of the annealed $\mathrm{GaN}: \mathrm{Mg}$ layers. At each of the points symbol of the sample and the carrier concentration is given. Dashed line indicates value of the total luminescence intensity of unannealed sample.

indicate that $\mathrm{Mg}$ acceptors which were activated in lower temperatures become passivated again. By secondary ion mass spectroscopy (SIMS) profiling measurements it was found that also oxygen is present in the annealed samples. It turns out that in the sample annealed at $1500^{\circ} \mathrm{C}(\mathrm{S} 85 \mathrm{~J})$ oxygen concentration is much higher than in the samples annealed at lower temperatures. The source of the oxygen is probably connected with contamination of nitrogen.

The conclusion is that oxygen donor may passivate the magnesium acceptor in GaN lattice. Annealing at high temperature removes hydrogen, but causes also in-diffusion of oxygen and passivation of $\mathrm{Mg}$-acceptors. This passivation may go via formation of $\mathrm{Mg}-\mathrm{O}$ complexes or compensation by distant donor-acceptor pairs. However, the lack of donor-acceptor luminescence in the sample annealed at $1500^{\circ} \mathrm{C}$ indicates that the formation of $\mathrm{Mg}-\mathrm{O}$ complexes probably takes place.

We gratefully acknowledge financial support from the Committee for Scientific Research, grant No. 7 T08A 06110.

\section{References}

[1] H. Amano, M. Kito, K. Hiramatsu, I. Akasaki, Jpn. J. Appl. Phys. 28, L2112 (1989).

[2] S. Nakamura, N. Iwasa, M. Senoh, T. Mukai, Jpn. J. Appl. Phys. 31, 1258 (1992).

[3] R. Dingle, M. Ilegems, Solid State Commun. 9, 175 (1971).

[4] O. Lagerstedt, B. Monemar, J. Appl. Phys. 45, 2266 (1974). 